Human and Animal Health

Vol.60: e17160436, January-December 2017 http://dx.doi.org/10.1590/1678-4324-2017160436 ISSN 1678-4324 Online Edition

\title{
Administration of venlafaxine after chronic methadone detoxification blocks post-depression relapse in rats
}

\author{
Meysam Fadaei-Kenarsary ${ }^{1,2}$, Hadi Fathi Moghaddam ${ }^{1,2}$, Seyyed Mohammad Taghi \\ Mansouri, $^{2,3}$, Yaghoob Farbood ${ }^{1,2 *}$. \\ ${ }^{I}$ Physiology Research Center, Ahvaz Jundishapur University of Medical Sciences, Ahvaz, Iran; ${ }^{2}$ Department of \\ Physiology, School of Medicine, Ahvaz Jundishapur University of Medical Sciences, Ahvaz, Iran; ${ }^{3}$ Department of \\ Pharmacology, School of Medicine, Ahvaz, Jundishapur University of Medical Sciences, Ahvaz, Iran.
}

\begin{abstract}
Relapse is highly prevalent after detoxification and depression. Due to the advantages of venlafaxine compared with other antidepressants, it is expected that venlafaxine administration may reduce relapse after detoxification and depression. This study aimed to evaluate the effects of venlafaxine on depression-induced relapse to morphine dependence after methadone detoxification. Eighty Sprague-Dawley rats were habituated and conditioned with morphine $(10 \mathrm{mg} / \mathrm{kg}$, S.C., for 4 days). After that, primary forced swimming and conditioned place preference (CPP) were tested. They were followed by methadone (70 $\mathrm{mg} / \mathrm{kg} / \mathrm{day}$, P.O., for 7 days) administration, extinguishing, forced swimming stress (FSS) and administration of venlafaxine ( $80 \mathrm{mg} / \mathrm{kg} /$ day, I.P., for 7 days). Finally same tests were performed. Administration of venlafaxine resulted in a decrement in final preference scores associated with a prime morphine injection (PMI) compared to the primary scores in methadone treated (MTD+) animals. In a swimming test, venlafaxine increased the amount of final floating and decreased final activity scores compared with the primary scores after administration of methadone. Venlafaxine reduced locomotor activity in MTD+ animals in the final test with PMI. There was a positive correlation between the final activity and preference scores after PMI. In conclusion, venlafaxine improved anxiety and depression-induced relapse on methadone detoxified rats.
\end{abstract}

Key words: Morphine, Methadone, Depression, Relapse, Venlafaxine, Rat

\footnotetext{
*Author for correspondence: farbood_y@yahoo.com
} 


\section{INTRODUCTION}

High prevalence of relapse after abstinence is the most disturbing after effect of opiate dependence treatment ${ }^{1}$. In the case of opiate addiction, there are effective treatments (such as buprenorphine therapy). However, even with these treatments, opiate-use relapse probability remains high ${ }^{2}$.

Some neurobiological targets in addiction treatment included: Dopamine receptor partial agonists, modulators of $\gamma$-aminobutyric acid signalling, Corticotropin releasing factor (CRF) antagonists, non-CRF targets and Glutamate modulators ${ }^{3}$.

Different types of drugs have been shown to be effective in treatment of addiction relapse such as Naltrexone ${ }^{4,5}$ (for opioids and alcohol relapse), Modafinil ${ }^{6}$ and Carbetocin ${ }^{7}$ (for opiate relapse), Aripiprazole ${ }^{5}$, Acamprosate ${ }^{8}$ and Disulfiram ${ }^{9}$ (for alcohol relapse).

Methadone therapy is usually used in licensed opioid-treatment. It has been a standard treatment for illegal opioid addicts in the past 40 years ${ }^{10}$. Methadone is a full agonist at the mu receptor ${ }^{11}$.

Fifty percent of those on methadone maintenance therapy were found to be suffering from depression ${ }^{12}$. It may be a driving force in motivating opiate-dependent individuals seek treatment ${ }^{13}$, particularly as depression is one of the prime causes of drug addiction relapse ${ }^{14}$.

Some antidepressants like Sertraline ${ }^{15}$ and Venlafaxine ${ }^{16}$ and substances with antidepressant activity such as Berberine ${ }^{17}$ and Saffron extract ${ }^{18}$ are effective in delaying or reducing addiction relapse irrespective of methadone administration.

Venlafaxine shows an attribute of selective inhibition for reuptake of norepinephrine and serotonin ${ }^{19}$. In severe depression, venlafaxine administration is an effective treatment. Also in resistant depression following treatment with a selective serotonin reuptake inhibitor (SSRI) it is a better choice than turning to another SSRI ${ }^{20}$.

Animal models are used for the study of special drug related behaviors, such as initial sensitivity measured by drug-induced locomotor behavior ${ }^{21}$.

Despite successful results for blocking opiate seeking activities ${ }^{6,7,16}$, the effect of administration of venlafaxine on post-depression relapse, depression and locomotion after chronic methadone detoxification and behavioral extinction have not been shown simultaneously. Relapse-inducing outcomes of drug-primes and acute administration of drugs are not easy to interpret. It is one of the shortcomings of a CPP version of the relapse model ${ }^{14}$.

This study aimed to determine the effects of venlafaxine on morphine relapse, depression-like behavior and locomotion post-depression (which occurred after chronic methadone administration and abstinence). Effects of morphine prime, chronic methadone (7 days) and venlafaxine (7 days) administrations were evaluated in this study too.

\section{MATERIAL AND METHODS}

\section{Animals}

Eighty young Male Sprague-Dawley rats (180-220 g; obtained from the Animal House of Ahvaz Jundishapur University of Medical Sciences) were housed (3-4 rats/cage) on a $12 \mathrm{~h}$ light-dark cycle (lights on at 7 a.m. to 7 p.m.). Water and standard feeding pellets were available for the rats at all times in the cage. The rats were kept in a temperature-controlled room $\left(23 \pm 2{ }^{\circ} \mathrm{c}\right)$. Animals were tested and conditioned during the light phase. They were handled $5 \mathrm{~min} /$ day for 7 days in the laboratory before the onset of experiments and were returned to their cages after undergoing each experimental protocol. All experiments were conducted in 
Effect of Venlafaxine on Post-depression Relapse

conformity with national standards and Ahvaz Jundishapur University of Medical Sciences (AJUMS) Guide for the Care and Use of Laboratory Animals. They were also approved by the local Institutional Ethics Committee (Ethics Code: AJUMS.REC.1392.327, 14 March 2012). All measures were undertaken to minimize animal suffering and the number of animals used.

\section{Drugs}

Morphine Sulfate Pentahydrate and Methadone Hydrochloride (racemic mixture, 99\% purity) were obtained from Temad Pharmaceutical Company (Tehran, Iran). Venlafaxine Hydrochloride (99.5\% purity) was obtained from Tehran Chemie and Purcina Pharmaceutical Companies (Tehran, Iran). All drugs were in the powder form.

Fresh stocks of morphine, methadone and venlafaxine were prepared daily according to the weight of animals in the experimental design. Morphine Sulfate Pentahydrate or Venlafaxine Hydrochloride was dissolved in the normal saline $(\mathrm{NaCl} 0.9 \%)$ so that the animals received the appropriate dose in a volume of $1 \mathrm{ml}$. Morphine (10 $\mathrm{mg} / \mathrm{kg}$ ) was injected subcutaneously (S.C.) for 4 days ${ }^{6}$. Methadone Hydrochloride $(70 \mathrm{mg} / \mathrm{kg}$ ) was dissolved in sucrose solution $3 \%(\mathrm{w} / \mathrm{v})$ (to reduce the bitter taste of methadone) in the concentration of $0.5 \mathrm{mg} / \mathrm{ml}$. It was administered orally (in drinking water) for 7 days ${ }^{22}$. Venlafaxine Hydrochloride $(80 \mathrm{mg} / \mathrm{kg})$ was dissolved in the normal saline $(\mathrm{NaCl} 0.9 \%)$ and injected intraperitoneal (I.P.) for 7 days ${ }^{23}$. The route of administrations was based on the volume of drug and vehicle.

\section{Measures}

Conditioned Place Preference Apparatus and Paradigm

Two rectangular Plexiglas test apparatuses (Borj Sanat Co., Tehran, Iran), each consisting of three distinct chambers ${ }^{6,16,24}$ were used with some modifications. Conditioning chambers differed in paint (wall color) and texture (size and shape of pores in bottom sheet) cues. The inner walls of one side chamber $(30 \mathrm{~cm}$ length $\times 30$ $\mathrm{cm}$ width $\times 35 \mathrm{~cm}$ height) were white with a fine pored rough grid floor. The other side chamber ( $30 \mathrm{~cm}$ length $\times 30 \mathrm{~cm}$ width $\times 35 \mathrm{~cm}$ height) had vertical black and white striped walls with a quadrangular pored (each pore $1 \mathrm{~cm}^{2}$ ) floor. Medial chamber ( $30 \mathrm{~cm}$ length $\times 15 \mathrm{~cm}$ width $\times 35 \mathrm{~cm}$ height) had gray inner walls and a black iron floor. All the walls and 3 floors were washable. Side chambers were separated from the medial one via guillotine-like doors. A dim illumination (40 Lux, by Luxmeter, TES1336, Taiwan) was used on the CPP boxes.

Conditioning was performed in silence. Time spent in each chamber was recorded via offline observation using a digital camera (Sony, DSC-W570, Japan, 2011) set up overhead on the CPP box and two chronometers (Fox40, China). An animal was considered in a chamber whenever all its four limbs were in the chamber.

A preconditioning test was used in order to determine the unconditioned place preference. The two guillotine-like doors were removed so that the animal could access all chambers. When an animal showed an innate preference to each side chamber in the 15 min preconditioning test, the animal was excluded from the study. Eight conditioning sessions were held on 4 consecutive days. Morphine sulfate (10 $\mathrm{mg} / \mathrm{kg}$ ) or normal saline (in equivalent volume as the vehicle) were injected subcutaneously (S.C.) to the rats. Animals were allocated separately in a specific side chamber (while the guillotine-like doors were closed) in the CPP box for $30 \mathrm{~min}$ after each injection. A $5 \mathrm{~h}$ interval existed between morning and afternoon injections. The drug-paired chamber and order of injection of the drug and the vehicle were counterbalanced across animals. Morphine and saline injection sessions 
were alternatively changed in the morning and afternoon. Animals that had received morphine in the morning, receive saline in the afternoon (on $1^{\text {st }}$ conditioning day). They received saline in the morning and morphine in the afternoon (on $2^{\text {nd }}$ conditioning day). Half of the animals received morphine in the black and white chamber, and the other half received it in the white chamber. One day without injection was necessary for induction of sensitization ${ }^{25}$.

Conditioned Place Preference Test (CPP Test): Animals may receive or not receive a morphine prime injection $(10 \mathrm{mg} / \mathrm{kg}$, S.C.) for the final CPP tests. They were placed separately in the middle gray chamber and guillotine-like doors were removed. Presence of animal in each chamber was videotaped by the digital camera. All 3 chambers were freely accessible to them for $30 \mathrm{~min}$. Then the animals were returned to their cages. The box (its floor and walls) was washed by camphorated ethanol (70 $\%$ ) and then with wet cotton. The CPP score (\%) was computed by the formula ${ }^{26}$ as follows: CPP Score $(\%)=($ Time spent in morphine-paired side/Total time spent in morphine and saline-paired sides) $\times 100$.

Eight to ten CPP sessions (1 session/day, each session lasted for $15 \mathrm{~min}$ ) without any injection were used for to extinguish the behavior. The guillotine-like doors were removed so that animals could freely roam in the chambers. Then the amount of time spent by each rat in each chamber was recorded. The sessions were continued until: 1) Rats spent less than $55 \%$ of the total time in the morphine-paired chamber during two consecutive days ${ }^{27}$. 2) The preference for the morphine-paired side decreased to less than $75 \mathrm{Sec}$ differences for 2 consecutive sessions ${ }^{6}$.

\section{Locomotor Activity}

The number of transitions into the side chambers in $30 \mathrm{~min}$ CPP tests was counted via offline observation as an indicator of locomotor activity ${ }^{25,28}$ or decision making behavior ${ }^{29}$.

\section{Forced Swimming Training, Test and Stress}

The rats were individually forced to swim for $10 \mathrm{~min}$ in a Plexiglas cylinder $(46 \mathrm{~cm}$ height and $20 \mathrm{~cm}$ diameter, Borj Sanat Co., Tehran, Iran) $24 \mathrm{~h}$ before forced swimming test ${ }^{30}$. The cylinder was filled with water $(30 \mathrm{~cm}$ depth). Water temperature maintained at $25 \pm 2{ }^{\circ} \mathrm{c}$. Then the rats were taken from the water, toweldried and transferred to a warm place and then returned to their cages.

On the test day, the rats were exposed to the cylinder for $6 \mathrm{~min}$. The behaviors in the six min forced swimming test were videotaped. Video files were coded and later scored only by an observer blind to the animal's individual treatment. The time sampling method (every $5 \mathrm{Sec}$, using a reverse timer, QC pass, 2012, China) was used for scoring animal's behaviors. Behaviors were scored as floating when the rats stopped struggling and moved only to keep their nose above the water surface. They were judged as active when the animals exhibited limb movement (climbing, swimming or diving). Every video was observed 3 times. Average scores of each behavior were entered into the statistical software. Seven days forced swimming stress ( $5 \mathrm{~min} /$ day) was used for induction of depressive-like behavior ${ }^{31}$.

\section{Experimental Design}

Experiments took 47-49 days per group and all experiments lasted 3 months due to inter and intra group time lag to avoid many overlaps in injections and experiments (Fig. 1). Animals were handled $5 \mathrm{~min} /$ day for 7 days in the laboratory. After preconditioning ( $8^{\text {th }}$ day) and conditioning protocols, one day without injection $\left(13^{\text {th }}\right.$ day, sensitization) was used. Animals were exposed to the primary tests at day 15 . Forced swimming and CPP tests were done in an hour apart (time needed to keep rats in a warm place). Then they were treated differently from the $16^{\text {th }}$ day. 
Effect of Venlafaxine on Post-depression Relapse

Administration of methadone (or its vehicle), the forced swimming stress (or without stress) and administration of venlafaxine (or its vehicle) were 3 distinct interventions. All rats underwent the extinguishing protocol (23-30/ $32^{\text {nd }}$ days). Forced swimming and venlafaxine interventions were performed after methadone intervention and extinguishing in order to remodel the clinical problem. Finally CPP tests were performed in 2 consecutive days in order to show the effect of the morphine prime injection. Final forced swimming test were performed in 2 consecutive days in order to equate acute effects of forced swimming tests on the CPP tests. Experimental groups are shown in the Table 1.

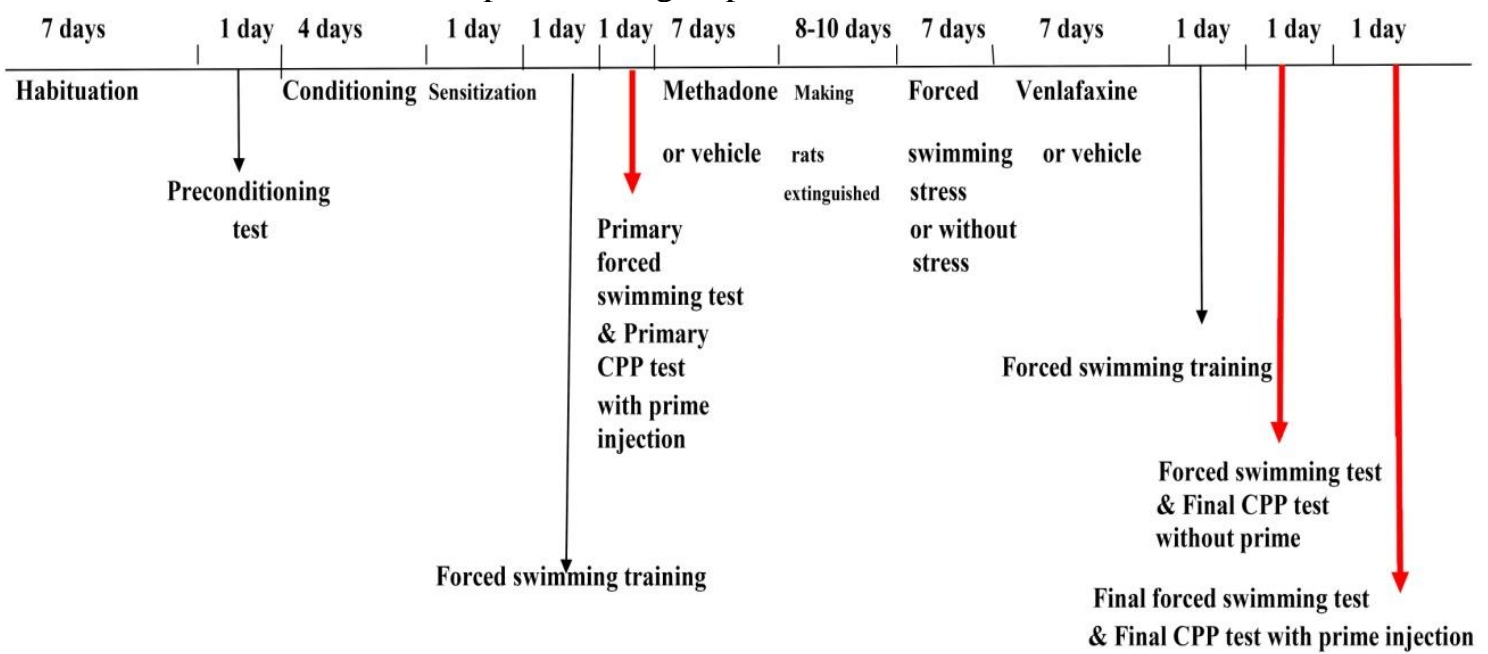

Figure 1 - Experimental design. The conditioned place preference paradigm, forced swimming test, steps of experiments and protocols has been demonstrated. The number of morphine and saline injections was equal in all animals either in conditioning or in the final CPP tests. Morphine administration was not an intervention between groups.

Table 1 - Experimental Groups

\begin{tabular}{|c|c|c|c|}
\hline \multirow[b]{2}{*}{ Groups } & \multicolumn{3}{|c|}{ Interventions } \\
\hline & Methadone & $\begin{array}{c}\text { Forced } \\
\text { swimming } \\
\text { stress }\end{array}$ & Venlafaxine \\
\hline MTD-FSS-VLX- & - & - & - \\
\hline MTD-FSS+VLX- & - & + & - \\
\hline MTD-FSS-VLX+ & - & - & + \\
\hline MTD-FSS+VLX+ & - & + & + \\
\hline MTD+FSS-VLX- & + & - & - \\
\hline MTD+FSS+VLX- & + & + & - \\
\hline MTD+FSS-VLX+ & + & - & + \\
\hline MTD+FSS+VLX+ & + & + & + \\
\hline
\end{tabular}

MTD=Methadone $(70 \mathrm{mg} / \mathrm{kg} / \mathrm{day}$, p.o., for 7 days), FSS=Forced swimming stress $(5 \mathrm{~min} / \mathrm{day}$, for 7 days), $\mathrm{VLX}=$ Venlafaxine $(80 \mathrm{mg} / \mathrm{kg} / \mathrm{day}$, i.p., for 7 days). The sign of + or - is representative of received or not received the treatment. Morphine administration was not an intervention between groups.

\section{Statistical Analysis}

The "Statistical Package for Social Sciences" (IBM SPSS 15.00, Chicago, IL, USA) was used for data analysis. GraphPad Prism 4.00 Software (San Diego California, USA) was used to draw histograms and linear regressions. Data were represented as means \pm SEM. Normalization of the data was determined using Kolmogrov-Smirnov test. Parametric data were analyzed by one-way Analysis of Variance (ANOVA). It 
was followed by post hoc tests (Tukey or LSD) whenever necessary. Significance was assumed at the $p<0.05$ level. Percentage changes of values were used whenever the raw test values were not significantly different among groups. Percentage changes of CPP scores in different test days (Fig. 2) were calculated for each group using the formula as follows: Percentage change of CPP scores $=\left(\left(\mathrm{CPP}\right.\right.$ score ${ }_{\text {next test }}{ }^{-}$ CPP score previous test)/CPP score previous test) $\times 100$. Percentage changes of floating or activity values in the forced swimming tests were computed using this formula: ((Final value-Primary value)/Primary value) $\times 100$.

Pearson (when the variable distribution was normal) or Spearman (when the variable distribution was not normal) correlations were used to determine the possible relationships among the final CPP scores, transitions, activity and immobility in animals.

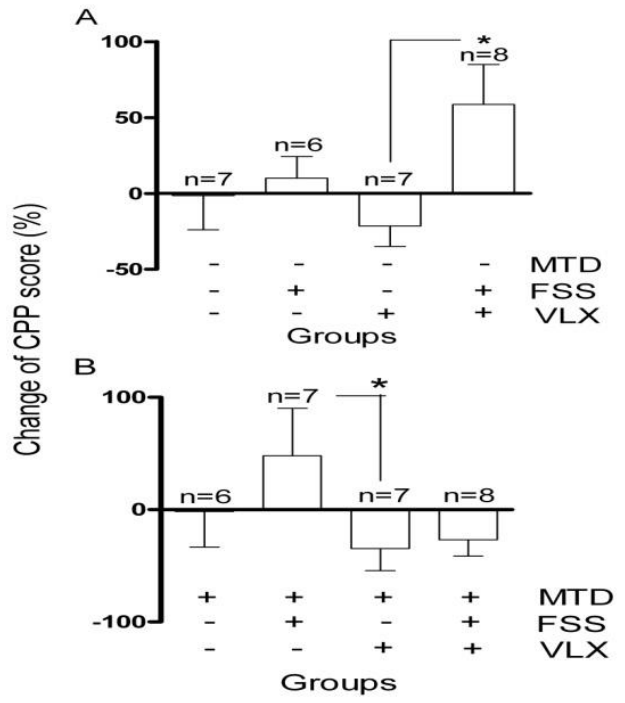

Figure 2 - Effects of forced swimming stress and venlafaxine on percentage changes of CPP score. MTD=Methadone, FSS=Forced swimming stress, VLX=Venlafaxine. The sign of + or - is representative of received or not received the treatment. A. Between final test with prime injection and final test without prime injection, ${ }^{*} \mathrm{p}<0.05,-80.204 \pm 27.774 \%$ difference, 1 -way ANOVA, Tukey HSD post-hoc test. B. Between final test with prime injection and primary test with prime injection, ${ }^{*} \mathrm{p}<0.05$, $-82.599 \pm 39.54 \%$ difference, 1-way ANOVA, LSD post-hoc test. The difference between percentage changes of CPP scores between MTD+FSS+VLX+ and MTD+FSS+VLX- values did not reach to the significant level $(\mathrm{p}>0.05,-74.709 \pm 39.544 \%$ difference), 1-way ANOVA, LSD post-hoc test. The number of morphine and saline injections was equal in all animals either in conditioning or in the final CPP tests. Morphine administration was not an intervention between groups.

\section{RESULTS}

Effects of forced swimming stress and Venlafaxine on percentage changes of conditioned place preference scores

Significant differences were observed in percentage changes of CPP scores in the primary and 2 final tests. Change of CPP scores between the final test with prime injection and the final test without prime injection differed significantly between MTD-FSS-VLX+ and MTD-FSS+VLX+ animals. No significant difference between the final test with prime injection and the final test without prime injection was observed among MTD-FSS-VLX-, MTD-FSS+VLX- and MTD-FSS+VLX+ animals (Fig. 2 A). Change in CPP scores between the final test with prime injection and the primary test with prime injection was significant merely between MTD+FSS+VLX- and MTD+FSS-VLX+ animals (Fig. 2 B). The effects of forced swimming stress and venlafaxine on crossing number and percentage changes of $\mathrm{CPP}$, floating and activity scores are shown in Table 2. 
Effect of Venlafaxine on Post-depression Relapse

Table 2. Effects of forced swimming stress and venlafaxine on crossing number and percentage changes of CPP, floating and activity scores in methadone treated animals.

\begin{tabular}{|c|c|c|c|c|c|c|}
\hline Groups & $\begin{array}{c}\% \\
\text { Changes } \\
\text { of CPP } \\
\text { Score } \\
\text { FA- } \\
\text { FW/FW }\end{array}$ & $\begin{array}{c}\% \\
\text { Changes of } \\
\text { CPP Score } \\
\text { FA-PA/PA }\end{array}$ & $\begin{array}{c}\text { \% Changes of } \\
\text { floating Score } \\
\text { F-P/P }\end{array}$ & $\begin{array}{c}\text { \% Changes } \\
\text { of activity } \\
\text { Score } \\
\text { F-P/P }\end{array}$ & $\begin{array}{c}\text { Crossing } \\
\text { number } \\
\text { FW }\end{array}$ & $\begin{array}{c}\text { Crossing } \\
\text { number } \\
\text { FA }\end{array}$ \\
\hline $\begin{array}{c}\text { MTD+FSS- } \\
\text { VLX- }\end{array}$ & $\begin{array}{c}30.31 \pm 46 . \\
78\end{array}$ & $\begin{array}{c}- \\
1.65 \pm 31.71\end{array}$ & $-66.02 \pm 3.33$ & $58.04 \pm 6.82$ & $\begin{array}{c}10.78 \pm 1 \\
87\end{array}$ & $\begin{array}{c}10.00 \pm 4.4 \\
5\end{array}$ \\
\hline $\begin{array}{c}\text { MTD+FSS+VL } \\
\mathrm{X}-\end{array}$ & $\begin{array}{c}11.21 \pm 35 \\
59\end{array}$ & $\begin{array}{c}47.95 \pm 42.3 \\
4\end{array}$ & $-82.10 \pm 5.12$ & $\begin{array}{c}\text { *18.26 } \pm 12.1 \\
0^{\mathrm{a} \# \#}\end{array}$ & $\begin{array}{c}16.00 \pm 2 . \\
74\end{array}$ & $\begin{array}{c}18.23 \pm 4.0 \\
4\end{array}$ \\
\hline $\begin{array}{c}\text { MTD+FSS- } \\
\text { VLX+ }\end{array}$ & $\begin{array}{c}- \\
11.53 \pm 9.7 \\
0\end{array}$ & $\begin{array}{c}{ }^{*}- \\
34.65 \pm 19.5 \\
5^{\mathrm{b} \#}\end{array}$ & $\underset{\text {,d\#\# }}{* * * * 25 \pm 10.60^{\mathrm{a}, \mathrm{b}}}$ & $\underset{\#}{* *} 7.01 \pm 9.46^{\mathrm{a} \#}$ & $\begin{array}{c}19.86 \pm 6 \\
08\end{array}$ & $\begin{array}{c}12.18 \pm 3.8 \\
4\end{array}$ \\
\hline $\begin{array}{c}\text { MTD+FSS+VL } \\
\mathrm{X}+\end{array}$ & $\begin{array}{c}- \\
10.32 \pm 19 \\
80\end{array}$ & $\begin{array}{c}- \\
26.76 \pm 14.6 \\
0\end{array}$ & $-71.30 \pm 8.45$ & $\underset{\# \#}{* 16.78 \pm 3.58^{\mathrm{a}}}$ & $\begin{array}{c}11.25 \pm 2 . \\
80\end{array}$ & $\begin{array}{c}* 8.10 \pm 2.5 \\
1^{\mathrm{b \#}}\end{array}$ \\
\hline
\end{tabular}

Values are means \pm S.E.M (n=6-8/group). $* \mathrm{P}<0.05, * * \mathrm{P}<0.01, * * * \mathrm{P}<0.001, \mathrm{a}=$ compared to MTD+FSS-VLXgroup, $\mathrm{b}=$ compared to MTD+FSS+VLX- group, $\mathrm{c}=$ compared to MTD+FSS-VLX+ group, $\mathrm{d}=\mathrm{compared}$ to MTD+FSS+VLX+ group, FA=Final test after prime injection, FW=Final test without prime injection, $F=F i n a l$, $\mathrm{P}=$ Primary, MTD=Methadone $(70 \mathrm{mg} / \mathrm{kg} / \mathrm{day}$, p.o., for 7 days $)$, FSS=Forced swimming stress $(5 \mathrm{~min} / \mathrm{day}$, for 7 days), VLX=Venlafaxine ( $80 \mathrm{mg} / \mathrm{kg} / \mathrm{day}$, i.p., for 7 days). The sign of + or - is representative of received or not received the treatment. \#1-way ANOVA, LSD post-hoc test, \#\#1-way ANOVA followed by Tukey-Kramer as post ANOVA test.

Effects of forced swimming stress and venlafaxine on percentage changes of floating and activity scores between the final and primary forced swimming tests

Percent changes of activity scores in MTD-FSS+VLX+ animals were significantly less than other MTD-FSS+VLX- animals. There were significant differences in percentage changes of floating and activity scores in methadone treated groups. Percentage changes of floating scores in the MTD+FSS-VLX+ animals were significantly higher than other methadone treated animals. On the other hand, percentage changes of activity scores in the MTD+FSS-VLX- animals were significantly higher than other methadone treated animals (Fig. 3). 


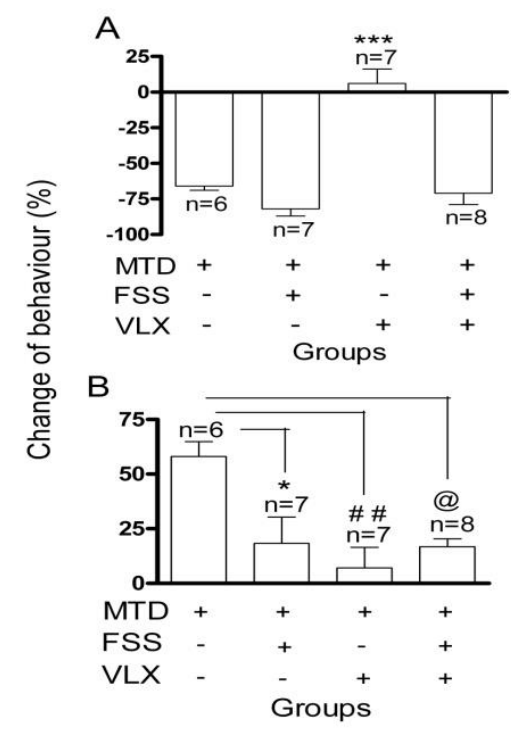

Figure 3 - Effects of of forced swimming stress (for 7 days, $6 \mathrm{~min} /$ day) and venlafaxine ( $80 \mathrm{mg} / \mathrm{kg}$, for 7 days, s.c.) on percentage changes of floating and activity scores between the final and primary forced swimming tests. MTD=Methadone, FSS=Forced Swimming Stress, VLX=Venlafaxine. The sign of + or - is representative of received or not received the treatment. A. Change of floating scores. $* * * p<0.001$, significantly more than values of MTD+FSS-VLX- $(72 \pm 9 \%$ difference), MTD+FSS+VLX- (88 $\pm 11 \%$ difference) and MTD+FSS+VLX+ (77 $\pm 10 \%$ difference) groups, 1-way ANOVA, Tukey post hoc test. B. Change of activity scores. ${ }^{*} \mathrm{p}<0.05$, versus MTD+FSS-VLX- (40 $\pm 4 \%$ difference). \#\#p $<0.01$ versus MTD+FSSVLX- (51 $\pm 6 \%$ difference). @ $\mathrm{p}<0.05$ versus MTD+FSS-VLX- (41 $\pm 4 \%$ difference), 1-way ANOVA, Tukey post-hoc test. The number of morphine and saline injections was equal in all animals either in conditioning or in the final CPP tests. Morphine administration was not an intervention between groups.

\section{Effects of forced swimming stress and venlafaxine on locomotor activity in the final conditioned place preference tests}

The numbers of crossings (entries) into the side chambers in 2 final CPP tests (without and then with morphine prime injection) were compared between the methadone controlled and methadone treated animals. Therefore four different states of locomotor activity have been shown in the Figure 4. Differences in the number of crossings did not reach to the significant level only in the final test without prime injection in methadone treated animals.
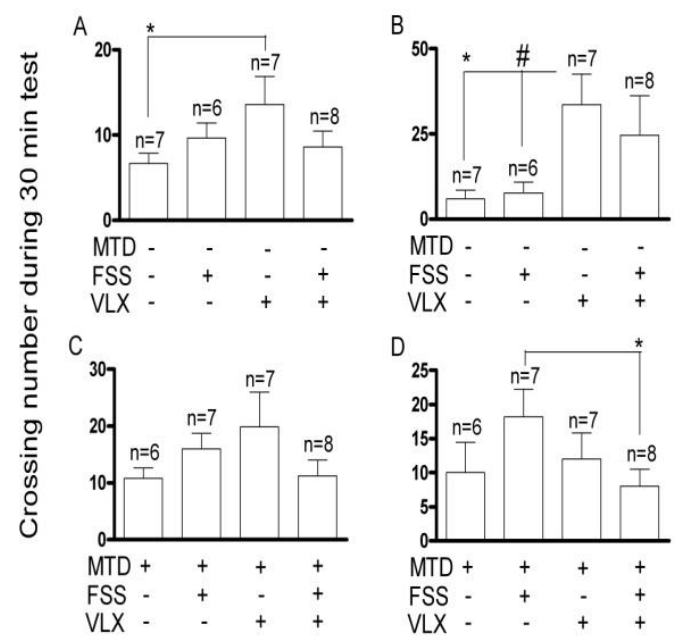

Figure 4 - Effects of venlafaxine ( $80 \mathrm{mg} / \mathrm{kg}$, i.p., 7 days) on crossing number in 2 final CPP tests. MTD=Methadone, FSS=Forced swimming stress, VLX=Venlafaxine. The sign of + or - is representative of received or not received the treatment. A. Crossing number in the final CPP test without morphine prime injection in methadone controlled rats. $* \mathrm{p}<0.05$, difference $=$ 
Effect of Venlafaxine on Post-depression Relapse

$-7 \pm 3$. The difference between MTD-FSS + VLX+ and MTD-FSS-VLX+ values was not significant $(p>0.05$, difference $=-5 \pm 3$ ). B. Crossing number in the final CPP test with morphine prime $(10 \mathrm{mg} / \mathrm{kg}$, s.c.) injection in methadone controlled rats. * $\mathrm{p}<0.05$, difference $=-28 \pm 13$. $\# \mathrm{p}<0.05$, difference $=-26 \pm 11$. The difference between MTD-FSS-VLX- and MTD-FSS+VLX+ values was not significant $(\mathrm{p}>0.05$, difference $=-19 \pm 13)$. C. Crossing number in the final CPP test without prime injection in methadone treated rats. The difference between MTD+FSS-VLX- and MTD+FSS-VLX+ values did not reach ( $p>0.05$, difference $=-9 \pm 5$ ) to the significant level. D. Crossing number in the final CPP test with prime injection in methadone treated rats. ${ }^{*} \mathrm{p}<0.05$, difference $=-10 \pm 5$. The difference between MTD+FSS-VLX- and MTD+FSS+VLX-values was not significant $(\mathrm{p}>0.05$, difference $=-8 \pm 6), 1$-way ANOVA, LSD post-hoc test.

\section{Correlation between the final activity and CPP scores}

CPP scores in the final test with prime injection were positively correlated $(37.4 \%$ correlation, $\mathrm{p}<0.05$, Pearson, $\mathrm{F}=4.312$, $\mathrm{df}=40$ ) with the final activity scores in forced swimming test (Fig. 5).

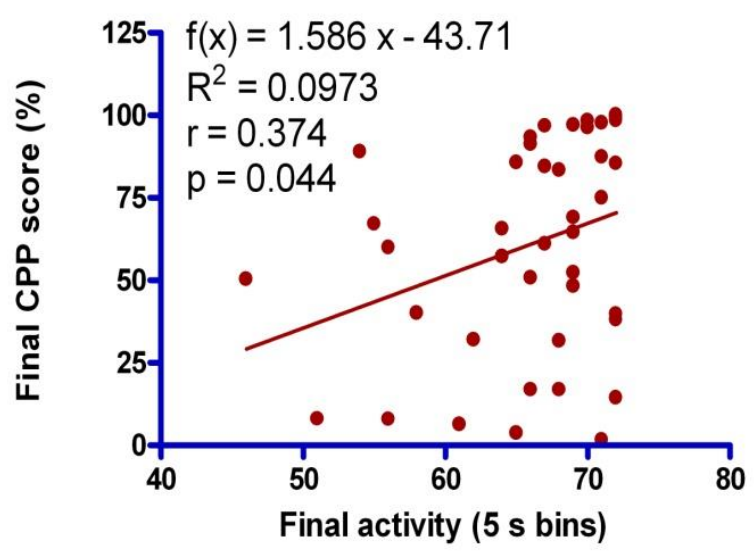

Figure 5 - Plot of CPP scores in the final test with morphine prime $(10 \mathrm{mg} / \mathrm{kg}$, s.c.) versus final activity scores in forced swimming test. The line represents linear regression for the values of methadone controlled and treated animals from different groups. $\mathrm{N}=42$.

\section{Correlation between CPP scores in the two final CPP tests}

The CPP scores in the final test with prime injection were positively correlated (72.3 $\%$ correlation, $\mathrm{p}<0.001$, Pearson, $\mathrm{F}=43.78$, $\mathrm{df}=40$ ) with $\mathrm{CPP}$ scores in the final test without prime injection (Fig. 6).

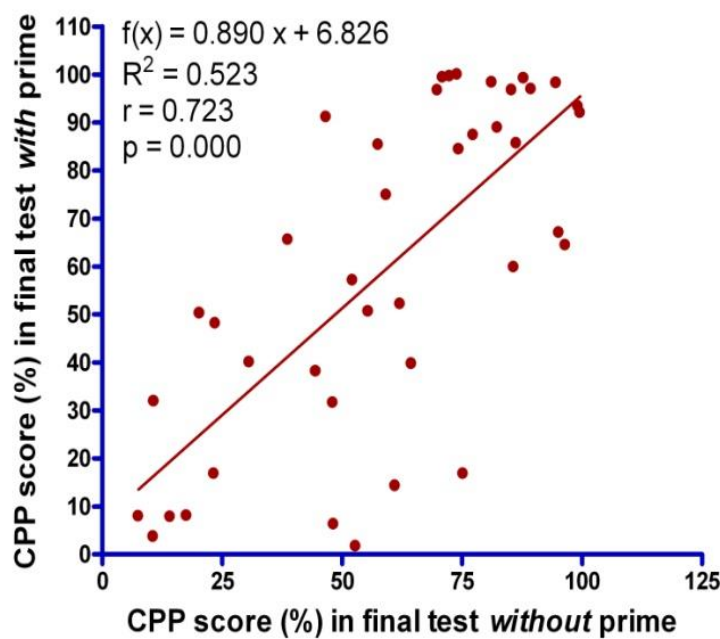

Figure 6 - Plot of the CPP scores in the final test with morphine prime $(10 \mathrm{mg} / \mathrm{kg}$, s.c.) versus CPP scores in the final test without prime injection. The line represents linear regression for the values of methadone controlled and treated animals from different groups. $\mathrm{N}=42$. 


\section{DISCUSSION}

The current study evaluates the relapse risk, depression status and possible relationships between them simultaneously after methadone detoxification. Decreases of CPP scores between the final and primary CPP tests with prime injection in MTD+FSS-VLX+ animals differed significantly from increases of CPP scores in MTD+FSS+VLX- ones; therefore administration of venlafaxine (80 $\mathrm{mg} / \mathrm{kg} /$ day, 7 days, i.p.) is helpful for decreasing post-depression reinstatement risk after chronic methadone detoxification. This effect was not significant between the final CPP test without prime injection and primary CPP test with prime injection; thus the effectiveness of venlafaxine in blocking forced swimming inducedmorphine primed reinstatement is more than morphine primed-reinstatement alone. It also suggests that administration of venlafaxine after chronic methadone detoxification could shift animal's tendency to decrease depression inducedmorphine primed relapse. This shift could be closely related to reward pathways. An advantage of this result is that venlafaxine administration could be effective in blocking relapse after chronic methadone administration especially in non-depressed rats. The present finding agrees with previous ${ }^{16}$ findings and may be useful after methadone detoxification programs.

Since a significant difference was observed between the percentage changes of CPP scores of MTD-FSS-VLX+ and MTD-FSS+VLX+ animals merely in the two final tests, it may confirm that forced swimming stress augments morphine-primed reinstatement via affecting reward pathways too. This may be due to "the role of cAMP Response Element Binding Protein (CREB), Brain Derived Neurotrophic Factor (BDNF), Dynorphin and Corticotropin-Releasing Factor (CRF) in mediating the cross-talk between stress and drugs of abuse" 32 .

Both stress and venlafaxine interventions in methadone treated animals could reduce the final activity as compared with the primary activity. Another surprising finding was that unlike force swimming stress, venlafaxine could increase the final floating compared with the primary one after administration of methadone. Venlafaxine could reduce final activity compared with the primary one in methadone-controlled animals that underwent forced swimming stress (MTD-FSS+). Swimming and climbing behaviors are functions of blockade of serotonin and norepinephrine transporters respectively ${ }^{33}$. It has been demonstrated that "expression of norepinephrine or serotonin transporters was not affected by chronic treatment with venlafaxine $(70 \mathrm{mg} / \mathrm{kg} / \mathrm{day}, 14$ days $)$, but immobility time in the forced swimming test was reduced" ${ }^{34}$. "Administration of venlafaxine $(32 \mathrm{mg} / \mathrm{kg} /$ day for 10 weeks) reduced floating time in rats" ${ }^{35}$. It has been reported that "methadone increases desensitization of 5-hydroxytryptamine $\left(5-\mathrm{HT}_{3}\right)$ receptor subtypes" ${ }^{36}$. Thus the increment of final floating in methadone treated animals might be attributed to this desensitization. It was previously established that floating time could be affected by anxiety ${ }^{37}$, bilateral lesion of the lateral septum ${ }^{38}$, serotonin and norepinephrine ${ }^{39}$, expression of brain derived neurotrophic factor mRNA in the hippocampus and micro RNA-16 ${ }^{40}$, 5-Hydroxytryptamine transporter genotype ${ }^{41}$, adrenocorticotropin and corticosterone levels ${ }^{42}$. Decrease of preference, increase of floating and it's possible relation with a decrease in anxiety are also supported with a previous study ${ }^{37}$. Therefore, evaluation of the role of these factors in specific regions could be helpful for determination of possible mechanisms involved in these observations.

Evaluation of the crossing number in the two final CPP tests demonstrated that administration of venlafaxine could enhance locomotor activity in methadone controlled animals. Unlike in methadone controlled animals, venlafaxine administration could reduce locomotor activity in methadone treated ones in the final test with prime injection. These results might be consistent with the involvement of 
mesolimbic dopamine release in drug seeking, reward and locomotion ${ }^{43}$. This also agrees with significant reductions observed in the final CPP scores and locomotor activity after prime injection in methadone and venlafaxine treated animals (MTD+FSS-VLX+ and MTD+FSS+VLX+). Another interpretation is that the more transition indicates more decision making behavior ${ }^{29}$. Therefore, it might be concluded that administration of venlafaxine could enhance decision making behavior in methadone controlled animals while it could reduce it in methadone treated animals. Further molecular evaluation of frontal cortex may provide more evidence for this possibility.

There was a significant positive correlation between the final activity in the forced swimming test and final CPP scores after prime injection. On the contrary, such a correlation was not observed between the final activity and final CPP scores without prime injection. It might be concluded that the less reinstatement risk, the less activity in the final forced swimming test. This idea might be supported at least by MTD+FSS-VLX+ and MTD+FSS+VLX+ animals. "Transgenic rats overexpressed human adenosine $A_{2 \mathrm{~A}}$ receptor in hippocampus, striatum and forebrain spend less time swimming and climbing" ${ }^{44}$; therefore the adenosine $\mathrm{A}_{2 \mathrm{~A}}$ receptor might be one of the candidates involved in this correlation.

The high positive correlation between the two final CPP scores might represent a strong correlation between «stress»-induced reinstatement and «stress+prime»induced reinstatement.

\section{CONCLUSION}

In conclusion, administration of venlafaxine could block relapse after chronic methadone detoxification. Venlafaxine improved anxiety and depression on methadone detoxified rats. The exact mechanisms involved in these observations are still not clear and further neurobiological and behavioral studies should open up new understandings of mechanisms to prevent opiate relapse.

\section{ACKNOWLEDGMENTS}

This paper was extracted as a part of Meisam Fadaei-Kenarsary M.Sc student thesis. This work was supported by research affairs of the Ahvaz Jundishapur University of Medical Sciences (AJUMS) (grant No. PRC-110) and was done in the Ahvaz Physiology Research Center. We acknowledge Dr. Ahmadi Angali for statistical advice. We also thank Professor William Winlow (University of Central Lancashire) for editing the manuscript. The authors have no conflict of interest.

\section{REFERENCES}

1- Nutt D, Lingford-Hughes A. Addiction: the clinical interface. Br J Pharmacol. 2008; 154: 397-405.

2- Ghitza UE. Needed relapse-prevention research on novel framework (ASPIRE model) for substance use disorders treatment. Front Psychiatry. 2015; 6 (37): 1-4.

3- Koob GF, Lioyd GK, Mason BJ. Development of pharmacotherapies for drug addiction: a Rosetta Stone approach. Nat Rev Drug Discov. 2009; 8 (6): 500-515. 
4- Lee JD, Friedmann PD, Kinlock TW, Nunes EV, Boney TY, Hoskinson RA, et al. Extended-release naltrexone to prevent opioid relapse in criminal justice offenders. $N$ Engl J Med. 2016; 374: 1232-1242.

5- Martinotti G, Di Nicola M, Di Giannantonio M, Janiri L. Aripiprazole in the treatment of patients with alcohol dependence: a double-blind, comparison trial vs. naltrexone. $J$ Psychopharmacol. 2009; 23: 123-129.

6- Tahsili-Fahadan P, Carr GV, Harris GC, Aston-Jones G. Modafinil blocks reinstatement of extinguished opiate-seeking in rats: mediation by a glutamate mechanism. Neuropsychopharmacology. 2010; 35: 2203-2210.

7- Zanos P, Georgiou P, Wright SR, Hourani SM, Kitchen I, Winsky-Sommerer R, et al. The Oxytocin analogue Carbetocin prevents emotional impairment and stress-induced reinstatement of opioid-seeking in morphine-abstinent mice. Neuropsychopharmacology. 2014; 39: 855-865.

8- Mason BJ, Goodman AM, Chabac S, Lehert P. Effect of oral acamprosate on abstinence in patients

with alcohol dependence in a double-blind, placebo-controlled trial: the role of patient motivation.

J Psychiatr Res. 2006; 40:383-393.

9- Van Zyl PM. Doctors' views of disulfiram and their response to relapse in alcoholdependent patients, Free State, 2009. Afr J Prm Health Care Fam Med. 2016; 8 (1), a1053.

10- Mauger S, Fraser R, Gill K. Utilizing buprenorphine-naloxone to treat illicit and prescription-opioid dependence. Neuropsychiatr Dis Treat. 2014; 10: 587-598.

11- Schuckit MA. Treatment of opioid-use disorders. N Engl J Med. 2016; 375: 357-368.

12- Peles E, Schreiber S, Naumovsky Y, Adelson M. Depression in methadone maintenance treatment patients: rate and risk factors. J Affect Disord. 2007; 99 (1): 213-220.

13- Baharudin A, Mislan N, Ibrahim N, Nik Jaafar NR. Depression in male patients on methadone maintenance therapy. Asia Pac Psychiatry. 2013; 5 (suppl 1): 67-73.

14- Aguilar MA, Rodriguez-Arias M, Minarro J. Neurobiological mechanisms of the reinstatement of drug-conditioned place preference. Brain Res Rev. 2009; 59 (2): 253277.

15- Oliveto A, Poling J, Mancino MJ, Williams DK, Thostenson J, Pruzinsky R, et al. Sertraline delays relapse in recently abstinent cocaine-dependent patients with depressive symptoms. Addiction. 2012; 107 (1): 131-141.

16- Lu L, Su WJ, Yue W, Ge X, Su F, Pei G, Ma L. Attenuation of morphine dependence and withdrawal in rats by venlafaxine, a serotonin and noradrenaline reuptake inhibitor. Life Sci. 2001; 69 (1): 37-46.

17- Vahdati Hassani F, Hashemzaei M, Akbari E, Imenshahidi M, Hosseinzadeh H. Effects of berberine on acquisition and reinstatement of morphine-induced conditioned place preference in mice. Avicenna J Phytomed, 2016; 6 (2): 198-204.

18- Hosseinzadeh H, Imenshahidi M, Arasteh A. Effects of aqueous saffron extract (Crocus sativus L.) on the acquisition and reinstatement of morphine-induced conditioned place preference in mice. Avicenna J Phytomed. 2012; 2 (1): 24-30.

19- Dhir A, Kulkarni SK. Venlafaxine reverses chronic fatigue-induced behavioral, biochemical and neurochemical alterations in mice. Pharmacol Biochem Behav. 2008; 89 (4): 563-571.

20- Lenox-Smith AJ, Jiang Q. Venlafaxine extended release versus citalopram in patients with depression unresponsive to a selective serotonin reuptake inhibitor. Int Clin Psychopharmacol. 2008; 23(3): 113-119.

21- Eisener-Dorman AF, Grabowski-Boase L, Tarantino LM. Cocaine locomotor activation, sensitization and place preference in six inbred strains of mice. Behav Brain Funct. 2011; 7: 29.

22- Liu, SJ, Evans, DB, Wang RIH. Analysis and differentiation of mechanism of tolerance to methadone in methadone-fed rats. Biochem Pharmacol. 1978; 28 (2): 287-293.

23- Capello CF, Bourke CH, Ritchie JC, Stowe ZN, Newport DJ, Nemeroff A, Owens MJ. Serotonin transporter occupancy in rats exposed to serotonin reuptake inhibitors in utero or via breast milk. J Pharmacol Exp Ther. 2011; 339 (1): 275-285. 
Effect of Venlafaxine on Post-depression Relapse

24- Harris GC, Wimmer M, Aston-Jones G. A role for lateral hypothalamic orexin neurons in reward seeking, Nature 2005; 437: 556-559.

25- Subhan F, Deslandes PN, Pache DM, Sewell RDE. Do antidepressants affect motivation in conditioned place preference?. Eur J Pharmacol. 2000; 408 (3): 257-263.

26- Liang J, Ma SS, Li YJ, Ping XJ, Hu L, Cui CL. Dynamic changes of tyrosine hydroxylase and dopamine concentrations in the ventral tegmental area-nucleus accumbens projection during the expression of morphine-induced conditioned place preference in rats. Neurochem Res. 2012; 37 (7): 1482-1489.

27- Billa SK, Sinha N, Rudrabhatla SR, Moron JA. Extinction of morphine-dependent conditioned behavior is associated with increased phosphorylation of the GluR1 subunit of AMPA receptors at hyppocampal synapses, Eur j Neurosci. 2009; 29 (1): 55-64.

28- Ma YY, Meng L, Guo CY, Han JS, Lee DY, Cui CL. Dose- and time-dependent, contextinduced elevation of dopamine and its metabolites in the nucleus accumbens of morphineinduced CPP rats. Behav Brain Res. 2009; 204: 192-199.

29- Karimi S, Karami M, Zardooz H, Salimi SH, Sahraei H. Biphasic Effects of Naloxone in the Rats Receiving Morphine Overdose A Place Preference Study. IJPR. 2011; 10 (3): 605-610.

30- Tian M, Mao RR, Wang LP, Zhou QX, Cao J, Xu L. Interaction between behavioral despair and addictive behaviors in rats. Physiol Behav. 2011; 102 (1): 7-12.

31- Gao D, Zheng Z, Han M, Tang X, Sun X. Findings of P-300 like potentials in rat model of depression following repeatedly forced swim stress. Int J Pharmacol. 2009; 72 (2): 160-165.

32- Briand LA, Blendy JA. Molecular and genetic substrates linking stress and addiction. Brain Res. 2010; 1314C: 219.

33- Reneric JP, Lucki I. Antidepressant behavioral effects by dual inhibition of monoamine reuptake in the rat forced swimming test. Psychopharmacology. 1998; 136: 190-197.

34- Zhao Z, Zhang HT, Bootzin E, Millan MJ, Donnell JM. Association of changes in norepinephrine and serotonin transporter expression with the long-term behavioral effects of antidepressant drugs. Neuropsychopharmacology. 2009; 34 (6): 1467-1481.

35- Darwish IE, Maklad HM, Diab IH. Behavioral and neuronal biochemical possible effects in experimental induced chronic mild stress in male albino rats under the effect of oral barley administration in comparison to venlafaxine. Int $J$ Physiol Pathophysiol Pharmacol. 2013; 5 (2): 128-136.

36- Deeb TZ, Sharp D, Hales TG. Direct subunit-dependent multimodal 5hydroxytryptamine3 receptor antagonism by methadone. Mol Pharmacol. 2009; 75: 908917.

37- Castro JE, Diessler S, Varea E, Marquez C, Larsen MH, Cordero MI, Sandi C. Personality traits in rats predict vulnerability and resilience to developing stress-induced depression like behaviors, HPA axis hyper-reactivity and brain changes in pERK1/2 activity. Psychoneuroendocrin. 2012; 37: 1209-1223.

38- Choi SH, Chung S, Choi JH, Cho YH, Kim JW, Kim JM, Kim HJ, Kim HJ, Shin KH. Changes in c-Fos expression in the forced swimming test: common and distinct modulation in rat brain by desipramine and citalopram. Korean J Physiol Pharmacol. 2013; 17 (4): 321-329.

39- Refaey HE, Amri HS. Effects of antidepressants on behavioral assessment in adolescent rats. Bahrain Med Bull. 2011; 33 (2): 1-12.

40- Bai M, Zhu X, Zhang Y, Zhang S, Zhang L, Xue L, Yi J, Yao S, Zhang X. Abnormal hippocampal BDNF and miR-16 expression is associated with depression-like behaviors induced by stress during early life. Plos One. 2012; 7 (10): e46921.

41- Schipper P, Nonkes LJP, Karel P, Kiliaan AJ, Homberg JR. Serotonin transporter genotype x construction stress interaction in rats. Behav Brain Res. 2011; 223: 169-175.

42- Hiramoto K, Yamate Y, Kobayashi H. Relationship between alteration of the peptide hormone levels and depression during the gestational period. Res J Endocrinol Metab. 2014; 2 : 1. 
43- Murphy NP, Lam HA, Maidment NT. A comparison of morphine-induced locomotor activity and mesolimbic dopamine release in C57BL6, 129Sv and DBA2 mice. $J$ Neurochem. 2001; 79 (3): 626-635.

44- Coelho JE, Alves P, Canas PM, Valadas JS, Shmidt T, Batalha VL, Ferreira DG, Ribeiro JA, Bader M, Cunha RA, do Couto FS, Lopes LV. Overexpression of adenosine $A_{2 A}$ receptors in rats: effects on depression, locomotion, and anxiety. Front Psychiatry. 2014; 5 (67): $1-8$

Received: February 03, 2016; Accepted: July 14, 2016 
Effect of Venlafaxine on Post-depression Relapse

\section{Erratum}

In Article "Administration of venlafaxine after chronic methadone detoxification blocks postdepression relapse in rats", with DOI number: http://dx.doi.org/10.1590/1678-4324-2017160436, published in journal Brazilian Archives of Biology and Technology, vol. 60, the 01 page.

That read:

“http://dx.doi.org/10.190/1678-4324-2017160436"

Read:

“"http://dx.doi.org/10.1590/1678-4324-2017160436" 